\title{
Adoption of Social Media by Small- and Medium-Sized Healthcare Enterprises
}

\author{
Silvia Zilber ${ }^{1, *}$ \\ ${ }^{1}$ Universidade Federal do ABC, São Paulo, SP, Brazil \\ Sonia Monken ${ }^{2, \dagger}$ \\ ${ }^{2}$ Universidade Nove de Julho, São Paulo, SP, Brazil \\ Filipe Quevedo-Silva ${ }^{3, \Omega}$ \\ ${ }^{3}$ Universidade Federal de Mato Grosso do Sul, Campo Grande, MS, Brazil
}

\begin{abstract}
Social media such as YouTube, Facebook, and Twitter can affect the way healthcare providers deliver their services. As low-cost tools, their use by small- and medium-sized enterprises (SMEs) in the healthcare sector could deliver competitive advantages. Several studies have shown that these tools are still underutilized by companies in this segment. Thus, the objective of the present study was to investigate which factors lead to the adoption of social media by SMEs in the healthcare sector in Brazil. To this end, a model for the adoption of organizational innovation was used in a causal study. A survey was conducted with 211 healthcare SMEs. The data analysis method was structural equation modeling (SEM), and SmartPLS 2.0 M3 software was used for the analyses. The results showed that both the perceived characteristics of the social media and the characteristics of the adopter are factors that contribute to the adoption of these media by the enterprises. Environmental influences were shown to not be relevant for the adoption of the media by the enterprises in the sample.
\end{abstract}

\section{KEYWORDS}

Innovation adoption, Social media healthcare, Small- and medium-sized enterprises, Health information management

CORRESPONDING AUTHOR

*Silvia Zilber

E-mail: silviazilber@gmail.com

†Sonia Monken

E-mail: sfmonken@hotmail.com

${ }^{\Omega}$ Filipe Quevedo-Silva

E-mail: filquevedo@gmail.com

Received: 19/06/2018.

Revised: 12/09/2018.

Accepted: 30/10/2018.

Published Online: 11/07/2019.

DOI: http://dx.doi.org/10.15728/bbr.2019.16.5.3 


\section{INTRODUCTION}

Healthcare is one of the most important economic activities in Brazil and around the world. It accounted for approximately 9\% of the country's GDP in 2011 according to statistics from the World Health Organization (OMS, 2014) and generated over 4.3 million direct jobs according to information from the Brazilian Institute of Geography and Statistics (IBGE) (Colucci, 2013), exceeding the recommendations of the Pan American Health Organization (OPAS, 2014).

Several transformations have occurred in the industrial medical complex (Gadelha, 2003), a healthcare sector that, according to the Ministry of Health (2011), is composed of productive activities in the healthcare field related to research, development and innovation and to the production, purchase, and sale of healthcare services, knowledge, and technology inputs.

In 2008, researchers at the Institute for Healthcare Improvement (IHI) described the Triple Aim as simultaneously improving the individual experience of care; improving the health of populations and reducing the per capita costs of care for populations.

The Triple Aim became a worldwide extension model considering that relevant measures such as health status experienced, rehospitalization rates, prevalence of chronic diseases and evolution in per capita health costs (Whittington, Nolan, Lewis, \& Torres, 2015).

This context is reinforced by individual health indicators, population health rates and health cost reduction indices. It can be affirmed that measuring the transition of population health levels in terms of these three goals is linked and aligned with the transition of interventions with system-wide improvements in health care being subtle to small care organizations. (Prior, McManus, White, \& Davidson, 2014).

For these transformations to be viable, healthcare providers have been undertaking significant investments, especially in the expansion and modernization of facilities, as well as in the qualification and training of professionals and the renewal and updating of information technology, among other areas (Colucci, 2013; Pedroso \& Malik, 2013).

Regarding the populations and their governments, the healthcare sector should improve the skills of human resources in primary care, broaden the qualifications of professionals and workers, and consolidate the sector's multidisciplinary work profile, further advancing innovations and fostering the expansion of access to information and to the development of telehealth mechanisms (Pan American Health Organization, 2012). Regarding the role of information technology in health, the 2012 report of the Pan American Sanitary Bureau states that it helps decision-making and strengthens regional healthcare systems, leading to improvements in the quality of life of citizens (Pan American Health Organization, 2012).

As for access to information, data published by the Pew Internet \& American Life Project (2006) show that "Internet users from the healthcare area" use the Internet at the same rate as users of Internet banking systems and blog readers.

In this context, according to Gagnon and Sabus (2015), as social media expands, healthcare providers need to adapt their professional communication media to meet consumers' expectations and needs, including communication through social media sites. Social media are collaborative technologies that enable communication, collaboration, and cooperation, making interaction between dispersed groups possible (Gupta et al., 2009; Bélanger \& Allport, 2008).

According to Li, Wang, Lin, and Hajli (2016), in recent years, social media such as YouTube, Facebook, and Twitter have drastically changed the healthcare industry, affecting the way healthcare providers deliver their services. According to these authors, social media act as a sort of "concierge" experience that responds quickly to patient issues, schedules appointments, and facilitates follow-up discussions. Thielst (2011) suggests that social media represent a tremendous 
low-cost opportunity for healthcare companies to listen to what patients and their families have to say. Thus, companies should identify individuals or small groups in social media and monitor these conversations through multiple channels.

In Brazil, as in other countries in the Americas and Europe, making facilities available via social media to users of healthcare providers is still limited and in the initial stages. Moreover, there is still no clear categorization of healthcare services offered via the internet in each country, mainly due to restrictive issues such as key infrastructure, legal normalization, culture, and values (TIC Saúde, 2015). While a number of studies in the literature have addressed the issue of the adoption of social media by consumers in the healthcare sector (Li, Wang, Lin, \& Hajli, 2016; Koteyko \& Hunt, 2016; Gagnon \& Sabus, 2015; Sarringhaus, 2011), fewer studies were found addressing the identification of factors that lead healthcare organizations to adopt social media in their business dealings.

In this scenario, Richter, Muhlestein, and Wilks (2014) investigated how hospitals use social networks by analyzing websites and Facebook pages. They found that seven out of ten hospitals use this tool and that $9 \%$ of hospitals with a Facebook page do not provide a link to it on their webpage. Richter et al. (2014) noted further that hospitals use Facebook as a dissemination strategy to educate consumers, to recognize employees, and to share news about awards won by the hospital. They concluded that this lack of engagement in the use of social media indicates a lost opportunity to improve customer service and quality of care, which would build loyalty.

Regarding the size of healthcare organizations, in a search for academic articles on the adoption of social media by small- and medium-sized enterprises (SMEs) in the healthcare sector, several articles were found focusing on the adoption of these media by small companies in various sectors (Perrigot et al., 2014; Durkin et al., 2013; Wamba \& Carter, 2014; He, Wang, Chen, \& Zha, 2015) but none regarding the adoption of these media specifically by SMEs in the healthcare sector.

However, in Brazil, this segment of companies is significant because, according to the National Registry of Health Establishments (CNES), out of a total of 6,150 general and specialized hospitals, only 71 are large and in the private sector, while 5,870 hospitals are medium-sized. This shows the relevance of this segment of companies in the healthcare sector.

Various authors have indicated, on the one hand, the possibility of using social media for the benefit of healthcare organizations, and have pointed, on the other hand, to the current underutilization of social media by these organizations.

About health information systems (SIS, SISNAC), social networks are still underutilized and health agencies such as the Ministry of Health define SIS and SISNAC as standardized tools for monitoring and collecting information data.

The SIS and SISNAC provide information for analysis and better understanding of important health problems of the population, subsidizing decision making at the municipal, state and federal levels (Pinto, Freitas, \& Figueiredo, 2018).

As information technologies and communication is based on data from work interactions, health care is based on clinical knowledge associated with listening skills and health monitoring. This proves that interactions between subjects are intrinsic to the development of health care. Therefore, the study would like to focus on the social media in healthcare.

Pinto et al. (2018) have also emphasized the fact that they are low-cost tools that are, therefore, suitable for the lower level of resources characteristic of SMEs. Thus, this work aimed to investigate the adoption of social media by SMEs in the Brazilian healthcare sector.

Consequently, the objective of the present study was to investigate which factors lead to the adoption of social media by SMEs in the Brazilian healthcare sector. 
Understanding that the use of social media can be considered an innovation for the sector, and to satisfy the objective of the present study, a model for the adoption of organizational innovation, adapted from Frambach and Schillewaert (2002) by Araújo and Zilber (2016), was used. This model was applied to 211 SMEs in the healthcare sector that participated in the "Projeto Bem-Estar e Saúde" (Wellness and Health Project) in Mato Grosso state, organized by SEBRAE, which is a network of nutritionists, physiotherapists, physicians, and diagnostic and therapeutic services (laboratories and imaging services) linked to the CNES's computerized database with national coverage.

The next sections will present the theoretical framework that is the basis of the present study and the proposed hypotheses, followed by the presentation of the method used and the results achieved, concluding with final considerations.

\section{REVIEW OF THE LITERATURE AND HYPOTHESES}

Many companies are using social media as a solution to various problems, such as improving relationships with customers (Hudson, Huang, Roth, \& Madden, 2016), promoting new products, and disseminating information (Lee $\& \mathrm{Ma}, 2012$ ). Thus, the adoption of social media in business can be understood as an organizational innovation, since, according to the Oslo Manual (OCDE, 2005), this type of innovation includes the first use of new organizational methods in the business practices or in the external relations of a company.

Concurrently, healthcare professionals are required to adhere to the standards of professional ethics in all types of relationships and interactions, including interactions on social media (Gagnon $\&$ Sabus, 2015). In their study, Gagnon and Sabus (2015) emphasize that they recognize the need for healthcare providers to adapt their communication to patients, due to the growth of information generated by social media; however, they found that healthcare organizations express apprehension regarding the use of professional social media, specifically in relationships with patients, due to ethical controversies.

In terms of the benefits generated using social media by healthcare providers, Li et al. (2016) state that this use can facilitate the dissemination of information not only in text format but also in more accessible formats, such as images and videos, which can be accessed at any time of the day.

However, despite their significant advantages in terms of providing healthcare information, social media still face many challenges in their adoption by healthcare users (Antheunis, Tates, \& Nieboer, 2013). Antheunis et al. (2013) observed that the greatest uses of these media are related to Twitter (60\%), for increasing knowledge and exchanging advice, and Facebook $(52.3 \%)$, for social support and exchange of advice. Healthcare professionals use LinkedIn (70\%) and Twitter for contact with colleagues and for marketing-related activities.

Regarding the use of social media by organizations to obtain a competitive advantage in their market, few articles were found.

Among these articles, Leek, Canning e Houghton (2016) focused on the use of Twitter in B2B relations, identifying three main uses of this medium: information sharing, problem solving, and public relations.

According to Richter et al. (2014), Facebook is underutilized by hospitals, and there is a considerable opportunity for consumer involvement at a low cost. For policymakers, there is greater use of social media by non-profit hospitals compared to for-profit institutions. If we assume that healthcare SMEs have few resources, there is an opportunity to use Facebook for this segment, which is understood to be an innovation for healthcare SMEs. To investigate what 
could lead healthcare organizations to adopt this type of innovation, various innovation adoption models can be used.

One important aspect of innovation is its diffusion: according to Rogers (1983), diffusion is the process by which an innovation is adopted and accepted by the members of a given community. Rogers (1983) was one of the first researchers to propose a model for the technological innovation adoption. A widely used model for innovation adoption is the Unified Theory of Acceptance and Use of Technology (UTAUT), developed by Venkatesh et al. (2003). The authors analyzed eight prominent innovation adoption models, suggesting the UTAUT model as being a synthesis of several models used, considering aspects related to psychology, sociology, and social cognitive theory. However, these models seek to understand the adoption of innovation by individual consumers and not by organizations.

In this context, Frambach and Schillewaert (2002) proposed a multi-level innovation adoption model that includes organizational and individual determinants. This model considers the perceived characteristic constructs of the innovation, characteristics of the adopter, environmental influences, marketing efforts of the suppliers, and the social network of the organization to determine the decision on the adoption of an innovation. Given that the analysis of the adoption should be adapted to the innovation or technology in question (Frambach \& Schillewaert, 2002), the model variables used were adjusted to specifically address the degree of social media use with respect to the following constructs: "perceived characteristics of the innovation," "characteristics of the adopter" and "environmental influences." These are the constructs that, according to the multilevel innovation adoption model, are directly related to the decision to adopt an innovation. In this study, the other constructs were disregarded due to their having an indirect influence on this decision.

According to Frambach and Schillewaert (2002), the construct "perceived characteristics of the innovation" identifies the benefits and difficulties perceived by the adopter. The model of Frambach and Schillewaert (2002) adapted by Araújo e Zilber (2016) was examined, and in the present study, the variables "relative advantage," "compatibility," "possibility for observation," and "uncertainty" were considered, which were reported by the authors as being influencers of the "perceived characteristics of the innovation" related to the use of social media. The "relative advantages" refer to the perceived benefits that the adoption of virtual social networks can bring to the organization. Better managerial understanding of the advantage of an innovation increases the likelihood of allocation of the managerial, financial, and technological resources needed to use this innovation. The variable "compatibility" can be expressed as the degree to which an innovation is perceived as being consistent with the existing values, past experiences, and needs of the potential adopters. The "possibility for observation" allows the results of an innovation to be visible to others. This visibility stimulates peer discussion about a new idea, such as the partners of an adopter. The "uncertainties" can be classified into three categories: a) technical - expresses the difficulty of the potential adopter in determining the reliability of the innovation and if it will function properly; b) financial - expresses the difficulty in determining if the adoption will be financially attractive; and c) social - understood as being the acceptability of conflicts in the organizational environment of the potential adopter in relation to the adoption of an innovation. Such uncertainties reduce the propensity to adopt an innovation, for example, the adoption of social media by companies. According to Frambach and Schillewaert (2002), and corroborating the results of the studies of Rogers (1983) and Moore and Benbasat (1991), the perception of members of an organization with regard to an innovation affects the propensity to adopt it; thus, we propose: 
Hypothesis 1 - The perceived characteristics of social media positively influence their adoption by small- and medium-sized healthcare organizations.

The construct "characteristics of the adopter" is composed of the variables "organizational structure" and "propensity for innovation." The "organizational structure" can be defined as a set of formal tasks assigned to individuals and departments; formal relationships of command, including lines of authority, decision-making responsibility, number of hierarchical levels, and the manager's range of control; and the design of systems to ensure the effective coordination of staff between departments (Daft, 2005). According to Chen and Chang (2012), an organization that has a high degree of centralization in decision-making and formalism and that is complex from the organizational perspective can make the adoption of social media in business processes difficult. According to Carayannis and Provance (2008), propensity for innovation involves a company's ability to capitalize on its own position based on the cultural acceptance of innovation, with reflections on the company's processes, routines, and capabilities. According to Rogers (1983), Tornatzky and Fleischer (1990), and Frambach and Schillewaert (2002), the characteristics of the adopter are primordial for the adoption of an innovation; the following hypothesis is thus proposed:

Hypothesis 2 - The characteristics of the adopter positively influence the use of social media by small- and medium-sized healthcare organizations.

The construct "environmental influences" consists of the variables "competitive pressure" and "externality of the network." According to Rogers (1983) and Tornatzky and Fleischer (1990), the external environment influences the adoption of an innovation; the following hypothesis is thus proposed:

Hypothesis 3 - Environmental influences have a positive influence on the use of social media by small- and medium-sized healthcare organizations.

"Competitive pressure" can be defined as "the degree to which the company is affected by competition in the market" (Zhu, Kraemer, \& Xu, 2006). "Network externality” occurs when the demand exerted by a person or organization may come to be influenced by other consumers who have already purchased the product (Pindyck \& Rubinfeld, 2005).

The 3 hypotheses are shown in the research model indicated in Figure 1.

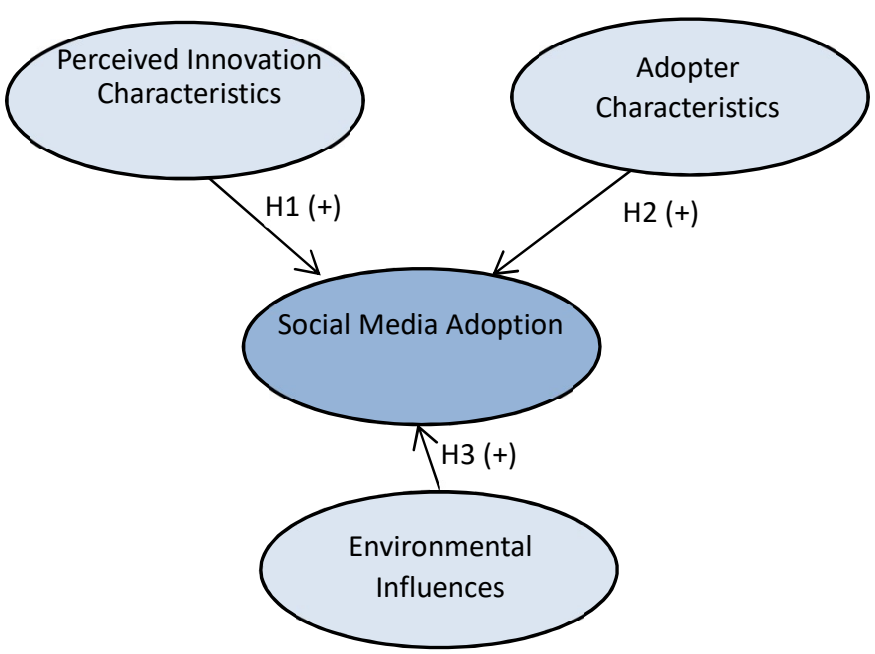

Figure 1. Research model with hypotheses. 


\section{METHOD}

The study type, the sample selection, and the data analysis procedures are presented below.

\subsection{STUdy Type}

According to the study type classifications presented by Gil (2002) and by Malhotra (2012), this study is classified as descriptive and causal in character because it aimed to identify the factors that determine the adoption of social media by companies. In this study, the "degree of intensity" with which this tool was adopted within the enterprise was used to measure the adoption of social media - the degree varied, from its use in only one area up to several areas or business processes of the enterprise. The use in only one area corresponds to a lower adoption intensity, whereas the more areas or processes that use these media, the greater the degree of adoption of the innovation.

Regarding the objective, this study is explanatory in character, seeking to explain relationships between variables (Gil, 2002). From the temporal perspective, the study is characterized as crosssectional (Malhotra, 2012).

\subsection{Sample Selection and Data Collection}

The sampling unit chosen was the small- and medium-sized companies in the healthcare sector that participated in the "Projeto Bem-Estar e Saúde" (Wellness and Health Project) in Mato Grosso state, through SEBRAE, the network of nutritionists, physiotherapists, physicians and diagnostic and therapy services (laboratories and imaging services) linked to the CNES's computerized database with national coverage.

The sampling technique was the non-probabilistic convenience sample, with the researcher being responsible for the decision regarding inclusion in the sample through legal entity categorization of small- and medium-sized, in accordance with the SEBRAE classification (Aaker, Kumar, Leone, \& Day, 2013; Malhotra, 2012; SEBRAE, 2015).

The target population included 211 small- and medium-sized companies or sole proprietors - the latter defined by federal legislation. The following types of companies were part of the sample: Diagnostic Centers, Imaging Centers, Specialty Clinics, Medical Clinics, Physiotherapy Offices, Psychology Offices, Doctor's Offices, Distributors of Medical and Hospital Products, Prescription Pharmacies, Home Care, Hospitals, Clinical Analysis Laboratories, Emergency Rooms, Dental Services, and Social Services.

Table 1 summarizes the profile of the sample in relation to the services offered.

As for the size, the sample had the profile shown in Table 2.

With regards to the minimum size of the sample, as the estimation method used (partial least squares) is partial, attention must be paid to the construct that has more causal relations with the others (receives more arrows) (Ringle, Silva, \& Bido, 2014). Thus, looking at Figure 1 (located in the section Review of the Literature and Hypotheses of this article), the construct "Intensity of social media use" receives three arrows (or has three predictors). A minimum sample size of 77 respondents was determined by using the calculation parameters - size of the mean effect $(0.15)$, power of the test (Power $=1-\beta$ ) of 0.80 , and level of significance of 0.05 - suggested by Cohen (1988 and 1992) for the areas of Applied Social Sciences and Behavior. This minimum sample size is well below the sample size of the present study. In addition, the free software G*POWER 3.19 (Faul, Erdfelder, Lang, \& Buchner, 2007) was used for sample size calculation. In both cases, the achieved sample of 211 companies was shown to be sufficient. 
Table 1

Profile of the Services of the Enterprises in the Sample

SECTOR

Clinical Analysis Laboratories

Total number

Dental Services

9

15

Diagnostic Centers

Distributors of Medical and Hospital Products 4

Doctor's Offices

Emergency Rooms

Home Care

Hospitals 16

Imaging Centers

Medical Clinics

Others

Overall total 211

Physiotherapy Offices 6

Prescription Pharmacies

Psychology Offices

Social Services 3

Specialty Clinics 78

Source: Data from the study.

Table 2

Size of the Enterprises in the Sample

SIZE

Total

Sole proprietor up to US\$234.252,00

Medium-sized enterprise - over UDS\$

$140.551 .210,01$

15

43

Small enterprise (EPP) - over US\$ 6.246.720.01 but

less than or equal to US\$140.551.210,00

Small enterprise (EPP) - over R $\$ 360,000.01$ but less

than or equal to US $\$ 140.551 .210,01$

Microenterprise (ME) over US\$ 234.252,01 but less

than or equal to US\$140.551.210,01

78

Overall total

211

Source: Data from the study.

For data collection, the survey method involved administering a questionnaire via the Internet using the SurveyMonkey tool, which is used for the creation and distribution of questionnaires. The respondents were the owners or directors of the enterprises.

The questionnaire was composed of questions measured on a seven-point scale (ranging from "totally disagree" to "totally agree"); for each variable, indicators created based on the literature were identified. For reasons of space, it was not possible to present all the indicators evaluated in the questionnaire.

The data were collected between August and December 2015. 


\subsection{Data Analysis}

The data analysis technique used was structural equation modeling (SEM) because it aims to achieve robust results regarding the possible relationships of the constructs represented in the model proposed for the study. The technique allows generic modeling used to test the validity of theoretical models that determine causal hypothetical relationships between the constructs (Hair, Anderson, Tatham, \& Black, 2009; Malhotra, Lopes, \& Veiga, 2014).

The software used to perform the analyses was SmartPLS 2.0 M3 (Ringle, Wende, \& Will, 2005; Ringle, Silva, \& Bido, 2014). The statistical technique used by the software is based on variances or partial least squares (PLS). It is used mainly in the construction of forecasting models when the factors are highly collinear, as well as to provide estimates between the latent variables and how these correlates according to the model and structure of the paths (Tobias, 1995; Trinchera \& Russolillo, 2010).

In this article, the measurement model was estimated, and the reliability, convergent validity, and discriminant validity of each variable were evaluated before proceeding to the evaluation and interpretation of the structural model.

\section{RESULTS AND DISCUSSION}

The first step for the adjustment of the model was the observance of its convergent validity. For this, the composite reliability (CR), the internal consistency - Cronbach's alpha (CA) test, and the convergent validity of each construct were verified via the average variance extracted (AVE) values.

To assess convergent validity, it is necessary to examine the AVE (Hair et al., 2011). An AVE value of 0.50 or more indicates an appropriate degree of convergent validity, meaning that the latent variable explains more than half the variance of its indicators (Tabachnick \& Fidel, 2001). It is important to note that this parameter does not apply to second-order constructs, which are not measured, as is the case of the construct "Perceived characteristics of innovation". The constructs showed acceptable levels of AVE indicating satisfactory convergent validity, in accordance with Table 3. Cronbach's alpha is an indicator of the internal consistency of a multi-item scale, widely used as an indicator of reliability (Lee \& Hooley, 2005), but with low sensitivity for evaluating the SEMs (Hair et al., 2014); thus, it should be considered with reservations. In fact, the CA test varies greatly with the size of the sample and with the number of variables or indicators present in each construct. For the CA, values from 0.6 to 0.7 are acceptable (Nunnally, 1978). The CR is more suitable for the PLS-PM because it prioritizes the variables according to their reliabilities. Values of 0.70 are considered to be satisfactory (Hair et al., 2014). Table 3 shows that the $\mathrm{CA}$ and $\mathrm{CR}$ values are acceptable.

In the second step, the discriminant validity of the constructs was analyzed because, according to Campbell and Fiske (1959), a successful study requires constructs that represent concepts that are not highly correlated; that is, constructs must measure different things. One of the criteria most used to verify discriminant validity was proposed by Fornell and Larcker (1981). It compares the square roots of the AVE values of each construct with the (Pearson) correlations between the constructs (or latent variables). The square roots of the AVEs should be larger than the correlations of the constructs. In Table 4, all the AVE values - which are in the diagonal in yellow - are higher than the other correlations shown, thus indicating that the adjusted model has discriminant validity among the constructs. 
BBR

16

462

Table 3

Values for Composite Reliability (CR), Cronbach's Alpha (CA) Test, and Average Variance Extracted (AVE)

\begin{tabular}{lccc}
\hline Constructs & AVE & CR & CA \\
\hline Intensity of use of virtual & 0.540 & 0.853 & 0.785 \\
social networks & 0.561 & 0.863 & 0.801 \\
Compatibility & 0.510 & 0.861 & 0.807 \\
Organizational structure & 0.645 & 0.878 & 0.814 \\
Externality of the network & 0.629 & 0.000 & -0.403 \\
Uncertainty & 0.660 & 0.920 & 0.897 \\
Possibility for observation & 0.518 & 0.837 & 0.710 \\
Competitive pressure & 0.562 & 0.832 & 0.732 \\
Propensity for innovation & 0.575 & 0.904 & 0.875 \\
Relative advantage & &
\end{tabular}

Source: Data from the study.

Table 4

Evaluation of the Discriminant Validity

\begin{tabular}{|c|c|c|c|c|c|c|c|c|c|}
\hline Constructs & 1 & 2 & 3 & 4 & 5 & 6 & 7 & 8 & 9 \\
\hline $\begin{array}{l}\text { 1. Intensity } \\
\text { of the use of } \\
\text { social media }\end{array}$ & 0.7346 & & & & & & & & \\
\hline 2. Compatibility & 0.4900 & 0.7491 & & & & & & & \\
\hline $\begin{array}{l}\text { 3. Organizational } \\
\text { structure }\end{array}$ & 0.4360 & -0.1195 & 0.7139 & & & & & & \\
\hline $\begin{array}{l}\text { 4. Externality of } \\
\text { the network }\end{array}$ & 0.2829 & 0.2307 & 0.1056 & 0.8030 & & & & & \\
\hline 5. Uncertainty & -0.0716 & 0.2495 & -0.2285 & 0.4736 & 0.7934 & & & & \\
\hline $\begin{array}{l}\text { 6. Possibility for } \\
\text { observations }\end{array}$ & 0.4734 & 0.2968 & 0.4557 & 0.3297 & 0.1611 & 0.8123 & & & \\
\hline $\begin{array}{l}\text { 7. Competitive } \\
\text { pressure }\end{array}$ & 0.1316 & -0.0476 & 0.2950 & 0.4813 & 0.3006 & 0.3128 & 0.7199 & & \\
\hline $\begin{array}{l}\text { 8. Propensity for } \\
\text { innovation }\end{array}$ & 0.6418 & 0.6046 & 0.1934 & 0.4588 & 0.2632 & 0.4871 & 0.1810 & 0.7498 & \\
\hline $\begin{array}{l}\text { 9. Relative } \\
\text { advantage }\end{array}$ & 0.6625 & 0.5709 & 0.2747 & 0.4103 & 0.3637 & 0.6086 & 0.3896 & 0.6157 & 0.7580 \\
\hline
\end{tabular}

Source: Data from the study. Obs: This table shows the correlations between the first-order constructs from Figure 1. The values in gray (in the main diagonal) are the square roots of the AVE. The other values are the correlations between the constructs.

Finally, the values and significance of the Path Coefficients $(\Gamma)$, shown in Table 5 and Figure 2, were verified. To accept a $\Gamma$, one must test if the causal relations between the constructs are significant. To this end, Student's t-test is used, observing the test value (t-statistic). Values above 1.96 (extremes or critical region of Student's t-distribution) are considered significant at 5\% (Hair et al., 2014). Finally, the value of the adjusted model's overall quality indicator (GoF) was not calculated because recent studies have shown that it may yield erroneous results (Hair et al., 2014).

The confirmation of hypothesis 1 - that perceived characteristics of social media affect the decision of healthcare SMEs in using social media - agrees with what has been described in 
Table 5

Analysis of the Path Coefficients and the p-values

\begin{tabular}{llcccc}
\hline Hypotheses & \multicolumn{1}{c}{ Causal relationships } & $\Gamma$ of path & $\begin{array}{c}\text { Value of } \\
\text { Student's t-test }\end{array}$ & p-value & Decision \\
\hline $\mathrm{H} 1+$ & $\begin{array}{l}\text { Perceived characteristics } \\
\text { of the innovation } \\
\rightarrow \text { Intensity of social media use }\end{array}$ & 0.424 & 8.685 & $<0.001$ & Confirmed \\
$\mathrm{H} 2+$ & $\begin{array}{l}\text { Characteristics of the adopter } \\
\rightarrow \text { Intensity of social media use } \\
\mathrm{H} 3+\end{array}$ & 0.498 & 8.320 & $<0.001$ & Confirmed \\
& $\begin{array}{l}\text { Environmental influences } \\
\rightarrow \text { Intensity of social media use }\end{array}$ & -0.136 & 1.238 & - & Rejected \\
\hline
\end{tabular}

Note: Level of significance adopted was $0.05(\alpha=0.05)$.

Source: Data from the study.

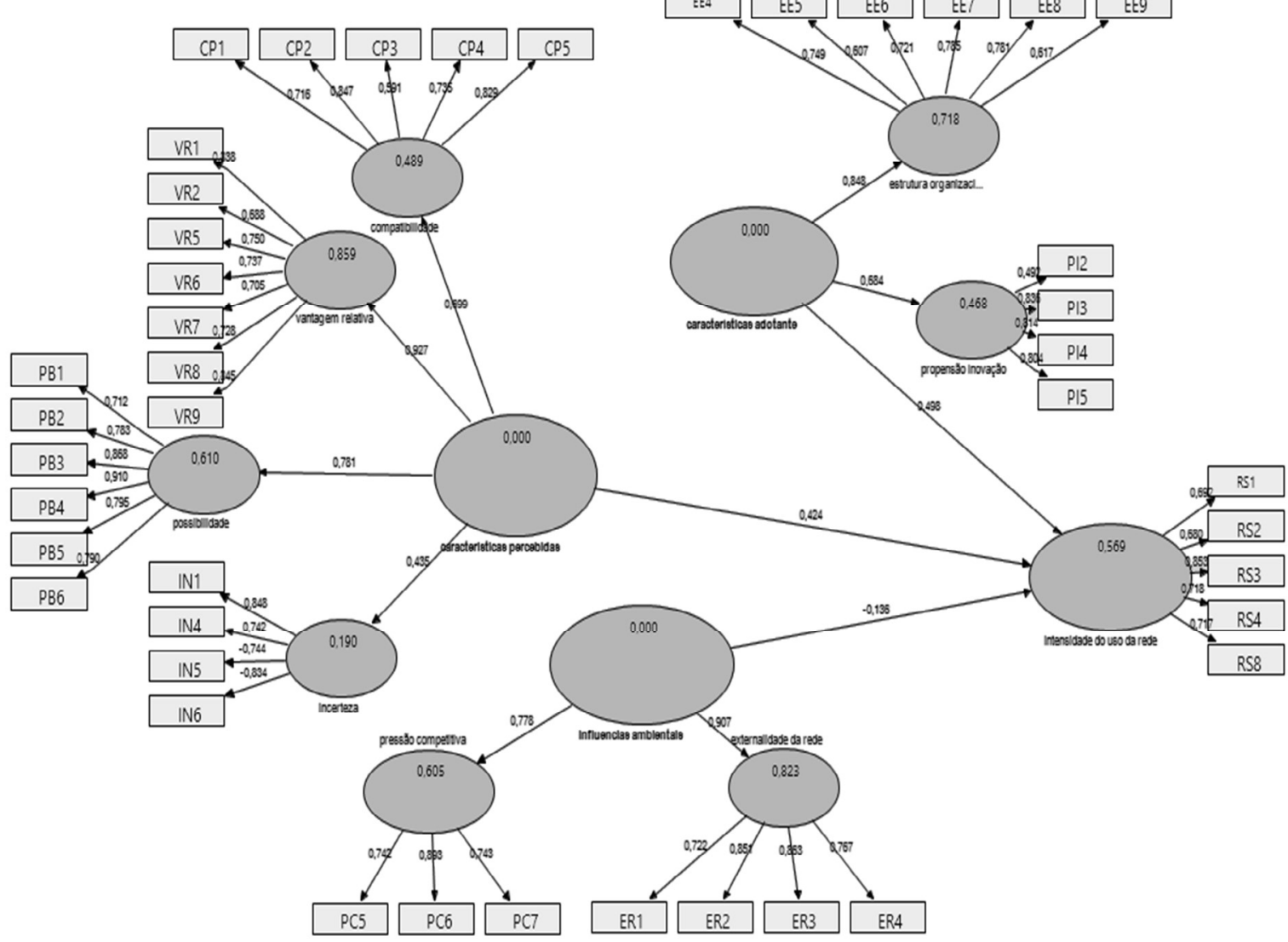

Figure 2. Structural and measurement model with $\lambda, \beta$, and $\mathbf{R}^{2}$ standardized.

Source: Data from the study.

the literature because, according to Li et al. (2016), two thirds of physicians use social media for professional purposes and $60 \%$ of them use these media to follow what their colleagues are sharing and to facilitate the speed of communication and collaboration among clinicians. These characteristics perceived by the healthcare professionals reflect on the behavior of their companies, facilitating the ability to observe the benefits deriving from this innovation as well as the compatibility of this tool with the procedures that they had already been using. The relative advantage of this use is also evident when professionals in the area perceive beneficial uses of social media, as cited by Richter et al. (2014) when commenting on the possibility of hospitals using 
Facebook to educate their clients, for example. The perceived advantage of using social media is also corroborated by Sarringhaus (2011), who views social media as a competitive advantage in connecting healthcare organizations with their patients and in recruiting and retaining employees from the millennial generation amid the generational shift occurring in the teams of healthcare corporations.

According to Lim (2016), "participatory medicine through social media contributes to continuous improvement in patient outcomes because physicians are able to engage in and contribute to real-time knowledge advancement conveniently as well as to facilitate more rapid adoption of the best, and most up-to-date medical and health care practices."

This statement shows one of the most important perceived advantage by the adopters of social media in healthcare: the promptness and readiness to answer the patient's needs.

The confirmation of the hypothesis that the characteristics of the adopter - defined by the variables "organizational structure" and "propensity for innovation" - affect the propensity to use social media (hypothesis 2) can be explained by Chen and Chang (2012), who assert that companies with very complex organizational structures may have greater difficulty accepting innovations. Given that SMEs are characterized by more flexible structures, with a lower degree of systematization of their processes, there is the possibility for greater agility in innovation adoption, as is the case of the companies in the sample, which includes companies with few hierarchical levels, thus enabling greater fluidity in decision-making.

Or, Tong, Tan, and Chan (2018), in their study about the factors that affect adoption of social media among physicians and small practice clinics, found that one characteristic of small clinics that affect the adoption of social media is the proper type of task and outcome performance, work practice and clinical workflow specific of these small businesses: one of the interviewed respondents said that this type of technology "facilitates clinical operations".

The rejection of the hypothesis that environmental influences affect the adoption of social media (hypothesis 3) can perhaps be explained by the fact that competitive pressure may not be the variable that leads companies to this adoption because, according to Antheunis et al. (2013), the reason patients use social media is to be able to search for information and exchange suggestions - the issue of competition is not a primary variable. Healthcare companies that can establish a good relationship with their patients thus need to consider their patients' expectations regarding the information they want to obtain. This also explains the small influence of network externalities: the relationship with the patient in terms of providing desired information is not affected by the need to offer a service just because a competitor offers it.

Or et al. (2018) found in their study that physicians responded that digitization was a trend and the clinical assistants said that they chose to use social media because they were told to use them by their physicians: this fact shows that the adoption is more related to the doctor's attitude than to external pressures, corroborating our findings.

\section{FINAL CONSIDERATIONS}

The objective of this article was to investigate which factors lead to the adoption of social media by SMEs in the healthcare sector in Brazil.

Thus, a model for adoption of organizational innovation was used, and the results confirmed two of the hypotheses and rejected a third.

The first hypothesis referred to the characteristics of the innovation: organizations adopt social media when they perceive that the media bring advantages to their relationships with customers, providing the customers ease in obtaining information and sharing knowledge. 
The second confirmed hypothesis refers to companies in the sample adopting the use of social media due to their own characteristics. Small companies are more flexible, have a more fluid organizational structure, and exhibit quicker decision-making. Moreover, owners normally use

social media to exchange knowledge with their peers and clients, thus facilitating adoption by the companies.

The third hypothesis (which was rejected) addressed the influence of the environment on the company's decision to adopt social media in its organizational processes, which can be explained by the fact that the reason patients use social media is to seek information and exchange suggestions - the issue of competition is not a primary variable considered by healthcare SMEs regarding the adoption of social media in their processes for relationships with patients.

The main contribution of the article is that it focuses on the use of social media by SMEs in the healthcare sector. Although there are a substantial number of SMEs in the healthcare sector, most studies focus more on the behavior of the individual healthcare consumer and on healthcare professionals - doctors, clinicians, and others.

The limitations of the study were imposed by the method itself: as a non-probabilistic sample was used, the results obtained here cannot be universally generalized.

As a suggestion for future studies, the method could be applied to other regions for comparative purposes.

It also could include exploring the perceptions of other stakeholders involved in this adoption, like patients. It could be employed a qualitative method such as case studies to better understand the factors that influence this adoption in more details and empirically examining the impact of factors derived from identified opportunities, and challenges on social media use in medical and health care (opportunities: quality of care, participatory medicine, emergency management (Lim, 2016; Tellini, Urdan, Monken et al, 2019), outcome performance (Or et al., 2018); challenges (trust, defamation, privacy). It could also be explored the effects of adoption of social media on user outcomes, like, for example, the physician and patient attitudes toward the use of social media in health care small companies. Research could also explore other intervenient variables that affect adoption, from studies about ecommerce adoption, for example, like the influence of cultural factors, among others.

\section{REFERENCES}

Aaker, D. A., Kumar, V., Leone, R., \& Day, G.S. (2013). Marketing research. (11th ed.). New York: John Wiley \& Sons.

Antheunis, M. L., Tates, K., \& Nieboer, T. E. (2013). Patients' and health professionals' use of social media in health care: motives, barriers and expectations. Patient Educ. Couns., 92(3), 426-431.

Araújo, J. B., \& Zilber, S. N. (2016). What factors lead companies to adopt social media in their processes: proposal and test of a measurement model. Brazilian Business Review, 13(6), 260-290.

Bélanger, F., \& Allport, C. D. (2008). Collaborative technologies in knowledge telework: an exploratory study. Information Systems Journal, 18(1), 101-121. doi:10.1111/j.13652575.2007.00252.x

Campbell, D. T., \& Fiske, D. W. (1959). Convergent and discriminant validation by the multitrait-multimethod matrix. Psychological bulletin, 56(2), 81. 
BBR

16

466

Carayannis, E. G., \& Provance, M. (2008). Measuring firm innovativeness: Toward a composite innovation index built on firm innovative posture, propensity and performance attribute. International Journal of innovation and Regional Development, 1(1), 90-107.

Chen, S. T., \& Chang, B. G. (2012). The effects of absorptive capacity and decision speed on organizational innovation: a study of organizational structure as an antecedent variable. Contemporary Management Research, 8(1), 27-50.

Cohen, J. (1992). A power primer. Psychological bulletin, 112(1), 155.

Cohen, J. (1988). Statistical Power Analysis for the Behavioral Sciences (2nd ed.). New York: Psychology Press.

Chauhan, G. S. (2011). Advertising through social media networks: let's catch up with the internet audience. International Journal of Research in Computer Application \& Management, $1(2), 112-114$.

Colucci, C. (2013). Um estudo exploratório sobre as estratégias de mercado adotadas em grandes hospitais gerais privados brasileiros. Dissertação (Mestrado em Administração) - Universidade de São Paulo, São Paulo.

Daft, R. L. (2005). Administração. 6a. ed. São Paulo: Thomson.

Domingo, M. C. (2010). Managing Healthcare Through Social Networks. Teach University. IEEE Computer Society. 43(7), 20-2.

Durkin, M., McGowan, P., \& McKeown, N. (2013). Exploring social media adoption in small to medium-sized enterprises in Ireland. Journal of Small Business and Enterprise Development, 20(4), 716-734.

Faul, F., Erdfelder, E., Lang, A. G., \& Buchner, A. (2007). G*Power 3: A flexible statistical power analysis for the social, behavioral, and biomedical sciences. Behavior Research Methods, 39, 175-191.

Fornell, C., \& Larcker, D. F. (1981). Evaluating structural equation models with unobservable variables and measurement error. Journal of Marketing Research, 18(1), 39-50.

Frambach, R. T., \& Schillewaert, N. (2002). Organizational innovation adoption: A multilevel framework of determinants and opportunities for future research. Journal of Business Research, 55, 163-176.

Gadelha, C. A. G. (2003). O complexo industrial da saúde e a necessidade de um enfoque dinâmico na economia da saúde. Ciência e Saúde Coletiva, 8(2), 521-535.

Gagnon, K., \& Sabus, C. (2015). Professionalism in a digital age: opportunities and considerations for using social media in health care. Physical Therapy, 95(3), 406.

Gil, A. C. (2002). How to develop research projects (4th ed.). São Paulo: Atlas.

Gupta, A., Mattarellib, E., Seshasaic, S., \& Broschaka, J. (2009). Use of collaborative technologies and knowledge sharing in co-located and distributed teams: Towards the 24-h knowledge factory. J Strat. Inf. System, 18(3), 147-161.

Hair, J. F., Anderson, R. E., Tatham, R. L., \& Black, W. C. (2009). Análise multivariada de dados (6th ed.). Porto Alegre: Bookman.

Hair, J. F., Hult, G. T. M., Ringle, C., \& Sarstedt, M. (2014). A primer on Partial Least Squares Structural Equation Modeling (PLSSEM). Los Angeles: SAGE Publications.

Hair, J. F., Ringle, C. M., \& Sarstedt, M. (2011). PLS-SEM: Indeed a silver bullet. The Journal of Marketing Theory and Practice, 19(2), 139-152. 
He, W., Wang, F. K., Chen, Y., \& Zha, S. (2015). An exploratory investigation of social media adoption by small businesses. Information Technology and Management. doi: 10.1007/s10799015-0243-3

Hudson, S., Huang, L., Roth, M. S., \& Madden, T. J. (2016). The influence of social media interactions on consumer-brand relationships: A three-country study of brand perceptions and marketing behaviors. International Journal of Research in Marketing, 33(1), 27-41.

Koteyko, N., \& Hunt, D. (2016). Performing health identities on social media: An online observation of Facebook profiles. Discourse, Context \& Media, 12.

Lee, C. S., \& Ma, L. (2012). News sharing in social media: The effect of gratifications and prior experience. Computers in Human Behavior, 28(2), 331-339.

Lee, N., \& Hooley, G. (2005). The evolution of "classical mythology" within marketing measure development. European Journal of Marketing, 39(3/4), 365-385.

Leek, S., Canning, L., \& Houghton, D. (2016). Revisiting the Task Media Fit Model in the Era of Web 2.0: Twitter use and interaction in the healthcare sector. Industrial Marketing Management, 54, 25-32.

Li, Y., Wang, X., Lin, X., \& Hajli, M. (2016). Seeking and sharing health information on social media: A net valence model and cross-cultural comparison. Technological Forecasting and Social Change. Forthcoming.

Lim, W. M. (2016). Social media in medical and health care: opportunities and challenges. Marketing Intelligence and Planning, 34(7), 964-976.

Malhotra, N. K. (2012). Pesquisa de marketing: uma orientação aplicada. Bookman.

Malhotra, N., Lopes, E. L., \& Veiga, R. T. (2014). Modelagem de equaçóes estruturais com Lisrel: uma visão inicial. Revista Brasileira de Marketing, 13(2), 28-43.

McNeill, L. H., Kreuter, M. W., \& Subramanian, S. V. (2006). Social environment and physical activity: a review of concepts and evidence. Social Science \& Medicine, 63(4), 1011-1022.

Ministério da Saúde. (2011). Secretaria de Vigilância em Saúde. Departamento de Análise de Situação de Saúde. Plano de açóes estratégicas para o enfrentamento das doenças crônicas não transmissiveis (DCNT) no Brasil 2011-2022.

Moore, G. C., \& Benbasat, I. (1991). Development of an instrument to measure the perceptions of adopting an information technology information. Information Systems Research, 2(3), 173-191.

Nunnally, J. C. (1978). Psychometric Theory. New York: McGraw-Hill Book.

OCDE. (2005). Manual de Oslo (Finep, Trans.).

Organização Pan-Americana de Saúde. (2014). CD53/5 (Rev. 22 de outubro de 2014). Retrieved from: http://www.paho.org/hq/index.php?option=com_docman \& task=doc_ download\&gid=27418\&Itemid=270\&lang=pt

Organização Mundial da Saúde. (2014). Guia de estudos. Retrieved from: http://sinus.org.br/2014/ wp-content/uploads/2013/11/OMS-Guia-Online.pdf

Or, C., Tong, E., Tan, J., \& Chan, S. (2018). Exploring factors affecting voluntary adoption of electronic medical records among physicians and clinical assistants of small or solo private general practice clinics. Journal of Medical Systems, 42(7), 1-12.

Pan American Health Organization. (2012). Health in the Americas: 2012 edition. Retrieved from: http://www.paho.org/saludenlasamericas/index.php?option=com_content\&view=arti cle\&id=7\&Itemid=3\&lang=en 
Pedroso, M. C., \& Malik, A. M. (2013). Cadeia de valor da saúde: um modelo para o sistema de saúde brasileiro. Ciência \& Saúde Coletiva, 17(10), 2757-2772.

Perrigot, R., Kacker, M., Basset, G., \& Cliquet, G. (2012). Antecedents of Early Adoption and Use of Social Media Networks for Stakeholder Communications: Evidence from Franchising. Journal of Small Business Management, 50(4), 539-566.

Pew Internet, \& American Life Project. (2006). Retrieved from: http://www.pewinternet. org/2006/10/29/part-1-113-million-internet-users-seek-health-information-online/

Pindyck, R. S., \& Rubinfeld, D. L. (2005). Microeconomics (6th ed.). São Paulo: Prentice Hall.

Pinto, L. F., Freitas, M. P. S. D., \& Figueiredo, A. W. S. A. D. (2018). Sistemas Nacionais de Informação e levantamentos populacionais: algumas contribuiçóes do Ministério da Saúde e do IBGE para a análise das capitais brasileiras nos últimos 30 anos. Ciência \& Saúde Coletiva, 23, 1859-1870.

Prior, M., McManus, M., White, P., \& Davidson, L. (2014). Measuring the "triple aim" in transition care: a systematic review. Pediatrics, peds-2014.

Richter, J. P., Muhlestein, D. B., \& Wilks, C. E. (2014). Social media: how hospitals use it, and opportunities for future use. J Healthc Manage, 59(6), 447-60.

Ringle, C. M., Silva, D., \& Bido, D. S. (2014). Modelagem de equaçôes estruturais com utilização do Smartpls. Revista Brasileira de Marketing, 13(2), 44-55.

Ringle, C. M., Wende, S., \& Will, S. (2005). SmartPLS (versão 2.0 M3 Beta) [Software]. Hamburg: SmartPLS.

Rogers, E. M. (1983). Diffusion of Innovations. New York: Free Press.

Sarringhaus, M. M. (2011). The great divide: Social Media's Role in Bridging Healthcare's Generational Shift. Journal of Healthcare Management, 56:4.

SEBRAE. (2015). Retrieved from: http://www.sebrae-sc.com.br/leis/default.asp?vcdtexto=4154

Serviço Brasileiro de Apoio às Micros e Pequenas Empresas. (2015). Retrieved from: http://www. sebrae-sc.com.br/leis/default.asp?vcdtexto $=4154$

Tabachnick, B., \& Fidell, L. (2001). Using multivariate statitstics (4a. ed.). Boston: Allyn and Bacon.

Tellini, L., Urdan, A. T., Monken, S. F., Bizarrias, F. S., \& Brandão, M. M. (2019). Os Impactos das Avaliaçóes do Cuidado de Saúde no Bem-Estar da Baixa Renda. Revista de Administração Contemporânea, 23(3), 351-372.

Tenenhaus, M., Vinzi, V. E., Chatelin, Y., \& Lauro, C. (2005). PLS Path Modeling Computational Statistics \& Data Analysis, 48, 159-205.

Thielst, C. B. (2011). Social media: ubiquitous community and patient engagement. Frontiers of Healthy Service Management, 28(2), 3-14.

TIC Saúde. (2015). Survey on the use of information and communication technologies in brazilian health care facilities: ICT in health 2015/São Paulo. Retrieved from http://cetic.br/ media/docs/publicacoes/2/tic_saude_2015_livro_eletronico.pdf

Tobias, R. D. (1995). An introduction to partial least squares regression. Proc. Ann. SAS Users Group Int. Conf., 20th, Orlando, FL, 2-5.

Tornatzky, L. G., \& Fleischer, M. (1990). The Processes of Technological Innovation. Lexington: Lexington Books. 
Trinchera, L., \& Russolillo, G. (2010). On the use of Structural Equation Models and PLS Path Modeling to build composite indicators. Working paper no. 30, Universita Degli Studi Di Macerata.

Venkatesh, V.; Morris, M.; Davis, G. \& Davis, F.D.( 2003) User acceptance of information technology: toward a unified view. MIS Quarterly, Minneapolis, v.27, n.3, p.425-478.

Wamba, S. F., \& Carter, L. (2014). Social media tools adoption and use by SMES: an empirical study. (Report) Journal of Organizational and End User Computing, 26(2), 1-17.

Wetzels, M., Odekerken-Schröder, G., \& Oppen, C. V. (2009). Using PLS path modeling for assessing hierarchical construct models: guidelines and empirical illustration. MIS Quarterly, 33(1), 177-195.

Whittington, J. W., Nolan, K., Lewis, N., \& Torres, T. (2015). Pursuing the triple aim: the first 7 years. The Milbank Quarterly, 93(2), 263-300.

Yu, B. (2011, Feb.). The emotional world of health online communities. Proceedings of the 2011 iConference (pp. 806-807). ACM.

Zhu, K., Kraemer, K. L., \& Xu, S. (2006). The process of innovation assimilation by firms in different countries: a technology diffusion perspective on e-business. Management Science, 52(10), 1557-1576. 